\title{
Sushruta: The Unrecognized Pioneer in Oral and Maxillofacial Surgery
}

\author{
Fareedi M Ali ${ }^{1}$, Alok Dubey ${ }^{2}$, Sameena Parveen ${ }^{3}$, Ather A Syed ${ }^{4}$, Sheetal Mujoo ${ }^{5}$
}

\begin{abstract}
Aim: To highlight the important contribution of Sushruta in the field of oral and maxillofacial surgeries.

Background: Sushruta is well recognized for his innovative methods in plastic surgery. Not much is written on his contribution in the field of oral and maxillofacial surgery and his contribution remains unrecognized.

Review results: Reference and passage in relation to oral and maxillofacial surgeries were identified by browsing "An English translation of the Sushruta Samhita" (Vol I, II, III) by Kaviraj Kunjala Bhishagratna and available literature from peer-reviewed indexed journals. An oral and maxillofacial surgical procedure like extraction of teeth, surgical extraction of wisdom teeth, fracture of jaws and nasal bone, dislocation of the mandible, use of wires to stabilize loose teeth and fractured jaws; rhinoplasty, otoplasty, cleft lip, and description of instruments like extraction forceps, suture needle, and materials has been described by Sushruta in his book Sushruta Samhita.

Conclusion: The contribution of Sushruta in the field of oral and maxillofacial surgery hardly got due recognition, which it deserved.

Clinical significance: The pioneering descriptions of oral diseases, the principles of oral and maxillofacial surgery in the Samhita remain valid in our contemporary understanding. He was the first surgeon who emphasized cadaver dissection for medical education, sterilization and asepsis procedures for surgery, use of wine as an anesthetic to reduce pain during the surgery, and also practical training for tooth extractions. Keywords: Oral and maxillofacial surgery, Sushruta, Sushruta Samhita.

World Journal of Dentistry (2020): 10.5005/jp-journals-10015-1777
\end{abstract}

\section{INTRODUCTION}

Dentistry has a long and fascinating history. From the earliest times, human beings have been plagued by dental diseases. Many of the remarkable techniques used in modern dentistry can be traced to the earliest period of human civilization. The ancient Indian medical science can be traced back to the Vedic period. The golden age of surgery in ancient India was mainly due to the historic contribution of Sushruta, the ancient surgeon, clinician, and teacher par excellence. Sushruta lived between 800 and $600 \mathrm{BC}$ and he was well recognized for his innovative methods in plastic surgery, ophthalmology, otolaryngology, obstetrics, and gynecology. Hence, he is called as "Father of Indian Surgery".,1,2 A limited conceptual work has been published on his contribution to the field of oral and maxillofacial surgery. The primary focus of this historical review is centered on Sushruta's surgical knowledge and highlights his vital contribution to the field of oral and maxillofacial surgeries.

Reference and passage of interest in relation to oral and maxillofacial surgeries were identified by browsing the authentic English translation of "Sushruta Samhita" by Kaviraj Kunjala Bhishagratna: Sushruta Samhita. Sutrasthanam. (Vol I), ${ }^{3}$ Sushruta Samhita, Nidana-Sthana, Sarira-Sthana, Chikitsita-Sthana, and Kalapa-Sthana. (Vol II). ${ }^{4}$ Sushruta Samhita. Uttara-Tantra.Vol (III). ${ }^{5}$ Published literature from peer-reviewed indexed journals was also searched on Sushruta and his contribution.

\section{Sushruta Samhita}

The work of Sushruta is compiled in a treatise called Sushruta Samhita (Sushruta's compendium) written in Sanskrit. It is one of the oldest surgical books that contains the first known description of basic surgical techniques. It is divided into six volumes. These six volumes contain 184 chapters, descriptions of 1,120 illnesses, 300
${ }^{1}$ Department of Oral and Maxillofacial Surgery, College of Dentistry, Jazan University, Jazan, Kingdom of Saudi Arabia

${ }^{2,4}$ Department of Preventive Dental Sciences, Jazan University, Jazan, Kingdom of Saudi Arabia

${ }^{3,5}$ Department of Oral and Maxillofacial Surgery and Diagnostic Sciences, Jazan University, Jazan, Kingdom of Saudi Arabia

Corresponding Author: Fareedi M Ali, Department of Oral and Maxillofacial Surgery, College of Dentisty, Jazan University, Jazan, Kingdom of Saudi Arabia, Phone: +966501225713, e-mail: faridi17@ rediffmail.com.

How to cite this article: Ali FM, Dubey A, Parveen S, et al. Sushruta: The Unrecognized Pioneer in Oral and Maxillofacial Surgery. World J Dent 2020;11(6):506-509.

Source of support: Nil

Conflict of interest: None

surgical procedures, classification of human surgery in 8 categories, over 120 surgical instruments, and around 700 drugs of animal, plant, and mineral origin. ${ }^{6-9}$

\section{Surgical Instruments}

Descriptions of various surgical instruments used by him are given in his book Sushruta Samhita. These instruments were constructed after the shape of beasts and birds and named after them like the crocodile forceps and hawk's bill forceps. ${ }^{8} \mathrm{He}$ also gives instructions on the fabrication of these instruments including the metal used, cleaning of these instruments by caustics and alkalis, maintenance of sharpness of edges of instruments. ${ }^{7}$

Operative procedures mentioned in Sushruta Samhita for the diseases of the oral cavity and maxillofacial region:

(0) Jaypee Brothers Medical Publishers. 2020 Open Access This article is distributed under the terms of the Creative Commons Attribution 4.0 International License (https://creativecommons.org/licenses/by-nc/4.0/), which permits unrestricted use, distribution, and non-commercial reproduction in any medium, provided you give appropriate credit to the original author(s) and the source, provide a link to the Creative Commons license, and indicate if changes were made. The Creative Commons Public Domain Dedication waiver (http://creativecommons.org/publicdomain/zero/1.0/) applies to the data made available in this article, unless otherwise stated. 


\section{Oral Surgical Procedures}

He described a variety of oral surgical procedures as given below:

- Epulis: Excessive overgrowth of the gingiva (epulis) should be excised. ${ }^{4}$

- Impacted third molar: He advocated extraction of impacted third molar teeth should be removed after giving an incision over the gums. ${ }^{4}$

- Intraoral sinus tracts of dental origin: He advocated a sinus arising from the root of a tooth, the overlying gum should be incised and the tooth should be extracted. ${ }^{4}$

- Broken pieces of teeth (remaining roots): Should be removed, otherwise the jaw bone becomes diseased and results in extraoral sinus formation. ${ }^{4}$

\section{Fractures and Dislocation}

- Mandibular fractures: He described conservative means of treating jaw fractures and advocated the use of manual manipulation, heat, and complicated bandaging to treat mandibular fractures. ${ }^{4,10}$

- Dento-alveolar fractures: Mobile tooth which is not fractured of a young person, should be plastered with a cooling paste on its outside. The tooth should be sprinkled or washed with cold water and treated with drugs having adhesive properties. The loose tooth of an old man should be extracted. ${ }^{4}$

- Nasal fracture: He described nose depressed (by a blow) should be raised with the help of a rod, while it should be straightened in a case of simple bending. Later two tubes, open at both ends, should be inserted into the nostrils (to facilitate the process of breathing) and the organ should be bandaged. ${ }^{4}$

- TMJ dislocation: He described the treatment of a dislocation of the joints of the jaw-bones should be fomented and duly set in their right position and bandaged. ${ }^{4}$

\section{Plastic Surgeries}

- Rhinoplasty: The description of the rhinoplasty operation in the Sushruta Samhita is precise. He described different methods of flap reconstruction of the nose by a pedicled cheek flap. He emphasized exact cutting of the pattern to the size of the defect on the cheek and accurate suturing of the flap to the nose. ${ }^{7}$

- Repair of cleft lip: Reconstruction of the congenital cleft lip has been described in the Sushruta Samhita.

\section{Anesthesia}

- He advocated wine before the operation to produce insensibility to the pain of the operation or asked the patient to inhale the fumes of burning Indian hemp-cannabis as an anesthetic. ${ }^{8,9}$

\section{Suturing}

- He used horsehair, fine thread, fibers of the bark of asmantaka tree (Bauhinia racemosa), threads made of hemp were also used were used as sutures. ${ }^{3-5}$

- Sushruta mentions four sorts of suturing: winding, sling, continued, and interrupted. ${ }^{11}$

- Suturing needles: straight, curved, and triangular suture needles are mentioned in his book.

\section{Anatomical Dissection of Cadavers}

- He mentions the process of dissecting a cadaver called Avagharshana. The first dead body is covered by Kusa grass and placed at the edge of a river, after 3 days it is taken out and successive layers of the epidermis, dermis, and the muscles beneath are dissected. ${ }^{12,13}$

- Sushruta Samhita mentions about selection criteria of a cadaver for dissection. ${ }^{3,4}$ (i) All and whole parts of the body present, (ii) a person who had not died due to poisoning, (iii) had not suffered from the chronic disease before death, and (iv) had not attained 100 years. $^{12,13}$

\section{Mock Surgeries}

- Mock or experimental surgeries have also been mentioned in Sushruta Samhita. The different experiments of excision were demonstrated on pumpkin-gourd, watermelon, and cucumber. The incision was demonstrated on a leather bag, the urinary bladder of an animal. ${ }^{14}$

The students practiced extraction of teeth on dead animals to enable them to appreciate the optimum grip and force causing the least damage to the surrounding structures. ${ }^{15}$

\section{Discussion}

One of the important and only surviving documents in connection with Sushruta Samhita is the Bower manuscript which was found in eastern Turkestan in 1890. Sushruta Samhita was translated into Latin by Hessler, in English by Hoernle; and into German by Muller. ${ }^{6,16}$ Kaviraja Kunjalal Bhishagratna published an English translation of Sushruta Samhita in three volumes (1907-1917). ${ }^{3,5}$ Consequently, the second edition was published in $1963 .{ }^{17}$

Sushruta Samhita contains a lot of innovative surgical procedures in the field of plastic surgery, ophthalmic surgeries, urology, obstetrics, and gynecology. His contribution remains unrecognized in the field of oral and maxillofacial surgery.

In chapter XVI under the heading Mukhya roga (diseases which affect the cavity of the mouth) ${ }_{i}^{4}$ Sushruta described diseases that affect the cavity of the mouth, lips, tooth proper, diseases of the root of the teeth, sinus at the root of the teeth, tongue, and palate. He classified these diseases and described the symptoms of these diseases.

Sushruta described the techniques for the extraction of teeth. $\mathrm{He}$ also advocated the surgical extraction of impacted teeth by giving an incision in the gums. ${ }^{4}$ He described two kinds of instruments "yantra" or "blunt" and "sastra" or "sharp". Among yantra, he described a special forcep "dantasanka" for extraction of teeth. ${ }^{18} \mathrm{He}$ also gave the description of forceps which were classified according to their shapes and function. Of particular interest, the cow horn and the pelican forceps are still used for extraction of anterior and posterior teeth and are the mainstay of the dentist all over the world even today.

In Sushruta Samhita, the principles of fracture treatment traction, manipulation, reduction, and stabilization were described; which holds good till this date. ${ }^{4} \mathrm{He}$ was the first person to describe the reduction of the dislocated mandible. ${ }^{4}$ The same method to manage acute dislocations is known today as the "conventional Hippocrates method". ${ }^{19}$ Sushruta described this treatment some 150 years before Greek physician Hippocrates. 
He described the treatment of fractured jaws by using complicated bandaging and bamboo splints covered with a mixture of flour and glue that were applied under the chin to immobilize the fractures..$^{10}$ The treatment of closed reduction of nasal fracture as mentioned by him is still practiced today. Here, the depressed bone is straightened by forceps and two tubes open at both ends inserted into the nostrils to facilitate the process of breathing and a plaster given outside. ${ }^{15}$ The principles laid down by Sushruta are still been practiced in many parts of rural India by bonesetters who have been practising the traditional method for ages.

The historic contribution of Sushruta is well recognized for his innovative method in rhinoplasty for an amputated nose (in the olden days, cutting off nose was a common form of punishment in females for infidelity and in males for a variety of offenses). His method for rhinoplasty is better known as the "Indian Method". ${ }^{20}$

The detailed description of rhinoplasty in his book Sushruta Samhita is amazingly meticulous. He used the superiorly based cheek flap. The problem with the cheek flap postoperatively is that this left a bad scar on the face. This flap was modified to median forehead flap by later surgeons from ancient India.

The Indian Method of Rhinoplasty was published in "Gentleman's Magazine of London and Historical Chronicle of London" in 1794 by James Findlay and Mr. Thomas Crusoe. They were the British Surgeons working in India. This Indian method of rhinoplasty is one of the preferred techniques for the reconstruction of noses around the world. ${ }^{21}$

Apart from nose reconstruction, he described the repair of a cut earlobe, piercing of earlobe, repair of a lacerated lip, wound care, and wound healing. Hence, he is been regarded by the fraternity of plastic surgery as the "father of plastic surgery". 20-22

The basic principles of surgery find a place in his writing. He laid the importance of giving incision in a single stroke with a suitable pressure on the knife to keep the edges sharp in the incised tissue. The principles of suturing laid down by him are still the same for ages. He advised sutures to be put neither too close nor too far apart. The tension caused by the sutures put far apart should be avoided and even sutures must not be placed too close, as there are chances of tissues getting cut through. ${ }^{15} \mathrm{He}$ is supposed to have used hemp fibers to ligate the vessels for controlling the bleeding. ${ }^{15}$ He used cauterization of the blood vessels to arrest hemorrhage during surgeries. ${ }^{15}$

Sushruta was the first person who had established the preservation of deceased and cadaver dissection for medical education, ${ }^{14}$ he quotes: "Any one, who wishes to acquire a thorough knowledge of anatomy, must prepare a dead body and carefully observe and examine all its parts". His advice to students on dissection: 'A pupil, otherwise well-read, but uninitiated, in the practice (of medicine or surgery) is not competent to take in hand the medical and surgical treatment of disease. ${ }^{19}$ It was Sushruta's belief that for one to be a skillful surgeon, one must first be an anatomist. ${ }^{23}$

His work cannot be ignored in the field of pain management, principles of suturing, suture materials, code of ethics for teachers and students, oath, informed consent, and anesthesia. ${ }^{14,15,24,25}$ All this was written some 150 years ago before the Greek Physician Hippocrates and two millenniums before European stalwarts like Celsius and Galen.

Sushruta insisted that before operating, the surgeons should shave off their beard, clip their nails, take a bath and wear clean, white clothes and he stressed antisepsis by fumigating the operating room with mustard, butter, and salt. ${ }^{20} \mathrm{He}$ recommended that the surgical equipment should be cleaned and disinfected with the fumes of specific medicinal plants. His observations on the occurrence of wound prevention are praiseworthy, as they were made long before Louis Pasteur and Joseph Lister in the 19 th century.

In Sushruta Samhita, we find a well-structured surgical training program for the students. ${ }^{24,25}$ He was the first teacher in oral surgery, who emphasized practical training of dental extractions. The students practiced extraction of teeth on dead animals to enable them to appreciate the optimum grip and force causing the least damage to the surrounding structures. ${ }^{15}$

He practiced surgeries in an era where no diagnostic facilities were available. The observation he made in his book on symptoms of the diseases are amazingly precise. He gives a detailed description of surgical techniques for making incision, excision, and teeth extraction. The treatment for jaw dislocation, conservative management of mandibular fractures, and various techniques in plastic surgery, such as sliding graft for small defect, rotation graft for a partial loss, and pedicle graft for complete loss of skin from an area deserves admiration. He left his greatest mark in the history of surgery through his rhinoplasty surgery.

\section{Conclusion}

The contribution of Sushruta in the field of oral and maxillofacial surgery hardly got due recognition, which it deserved. As we stand on the shoulders of our ancient giants who walked before us in the field of medicine, we must remember their contribution.

\section{References}

1. Raju VK. Sushruta of ancient India. Indian J Ophthalmol 2003;51:119122.

2. Tewari M, Shukla HS. Sushruta: the father of Indian surgery. Indian J Surg 2005;67:229-230.

3. Bhishagratna KL. An English Tranlation of The Sushruta Samhita, Sutrasthanam. vol. I, Calcutta: Kaviraj Kunjalal Bhishagratna; 1907.

4. Bhishagratna KL. An English Translation of The Sushruta Samhita, Nidana-Sthana, Sarira-Sthana, Chikitsita-Sthana and Kalapa-Sthana. vol. II, Calcutta: Kaviraj Kunjalal Bhishagratna; 1911.

5. Bhishagratna KL. An English Translation of the Sushruta Samhita, Uttara tantra. vol. III, Calcutta: S. L. BHADURI; 1916.

6. Shah S. Ophthalmology in ancient time - the Sushruta Samhita. J Clin Ophthalmol Res 2018;6(3):117-120. DOI: 10.4103/jcor.jcor_15_17.

7. Champaneria MC, Workman AD, Gupta SC. Sushruta: father of plastic surgery. Ann Plast Surg 2014;73(1):2-7. DOI: 10.1097/ SAP.0b013e31827ae9f5.

8. Bhattacharya S. Sushrutha - our proud heritage. Indian J Plast Surg 2009;42(2):223-225. DOI: 10.1055/s-0039-1699348.

9. Singh V. Sushruta: the father of surgery. Natl J Maxillofac Surg 2017;8(1):1-3. DOI: 10.4103/njms.NJMS_33_17.

10. Aziz SR. A history of the treatment of jaw fractures. J Mass Dent Soc 1993;42:200-203.

11. Mukhopadhyaya $G$. The surgical instruments of the Hindus, with a comparative Study of the surgical instruments of Greek, Roman, Arab and The modern European surgeons. Calcutta: Calcutta University Press; 1913.

12. Deepa B, Pushpalata M. Contributions of sushruta to anatomy. Anatomy J Afr 2014;3(2):362-365.

13. Singhal GD, Guru LV. Anatomical \& Obstetric Considerations in Ancient Indian Surgery. Banaras: Banaras Hindu University Press; 1973.

14. Saraf S, Parihar R. Sushruta: The First Plastic Surgeon in 600 BC The Internet Journal of Plastic Surgery 2006;4(2):1-7. 
15. Singh LM, Thakral KK, Deshpande PJ. Susruta's contributions to the fundamentals of surgery. IJHS 1970;5(1):36-50.

16. Mukhopadhaya G. History of Indian Medicine. Calcutta: Calcutta University Press; 1929. pp. 32-33.

17. Bhishagratna KL. An English translation of the Sushruta Samhita. Varanasi: Chowkhamba Sanskrit Series Office; 1963.

18. Borle RM. Text Book of Oral \& Maxillofacial Surgery. New Delhi: Jaypee Brothers Medical Publisher; 2014.

19. Jeevan L, Nitin V, Palvi G. Chronic protracted temporomandibular joint dislocation: a report of two cases along with systematic literature review. J Head Neck Phys Surg 2014;2(1):53-66.

20. Champaneria MC, Workman AD, Gupta SC. Sushruta: father of plastic surgery. Int J Sci Res 2016;5(3):663-668.
21. Kumar A, Kumar BN. The principles of surgical practice: sushruta samhita and its importance to present day surgery. J Surg Open Access 2020;6(2):1-2.

22. Bath K, Aggarwal S, Sharma V. Sushruta: Father of plastic surgery in Benares. J Med Biogr 2019; 27(1):2-3. DOI: 10.1177/0967772016643463.

23. Loukas M, Lanteri A, Ferrauiola J, et al. Anatomy in ancient India: a focus on the Susruta Samhita. J Anat 2010;217(6):646-650. DOI: 10.1111/j.1469-7580.2010.01294.x.

24. Puthumana PP. Through the mists of time: sushrutha, an enigma revisited. Indian J Plast Surg 2009;42(2):219-223. DOI: 10.4103/09700358.59285.

25. Kansupada KB, Sassani JW. Sushruta: the father of Indian surgery and ophthalmology. Doc Ophthalmol 1997;93(1-2):159-167.DOI: 10.1007/ BF02569056. 